\title{
Integrated Computational Materials Engineering of Magnesium
}

\author{
V.M. MILLER ${ }^{1,3}$ and S.R. AGNEW ${ }^{2,4}$ \\ 1.-Department of Materials Science and Engineering, North Carolina State University, \\ Raleigh, NC 27695-7907, USA. 2.-Department of Materials Science and Engineering, \\ University of Virginia, Charlottesville, VA 22904-4745, USA. 3.-e-mail: vmiller2@ncsu.edu. \\ 4.- -e-mail: sra4p@virginia.edu
}

Alloy and process design for magnesium are significantly complicated, relative to $\mathrm{Al}-$ and $\mathrm{Ni}$ based alloys (for which ICME has been most successfully employed), because $\mathrm{Mg}$-based alloys possess a hexagonal crystal structure. ${ }^{1}$ Fortunately, the modeling and experimental tools required to perform integrated computational materials engineering (ICME) of $\mathrm{Mg}$ have significantly advanced over the past few years. ${ }^{2,3}$ This special topic provides a compact review of some of those recent advances.

The opening article in this series is a review of recent progress of The Center for PRedictive Integrated Structural Materials Science (PRISMS Center) in developing critical infrastructure necessary for accelerated development of materials and processes. In this article, L.K. Aaegesen et al. discuss three pillars of the Center's ongoing efforts: integrated multiscale models of phase stability, microstructural evolution, and resulting mechanical performance, the Materials Commons data repository, and use cases that tie the models and existing data to ongoing scientific experiments. The use of these three pillars for predicting precipitate evolution and the resulting mechanical properties is illustrated with the example of $\mathrm{Mg}-\mathrm{Nd}-\mathrm{Y}$ alloys.

One of the key inputs to the development of physics-based predictive models of mechanical behavior is mesoscale experimental analysis of the role of precipitate distribution in plastic deformation. In the second manuscript, "Understanding the Strengthening Effect by $\mathrm{SS}_{1}$ Precipitates in Mg-Nd Using In Situ Synchrotron X-ray Diffraction" by Bijin Zhou et al. on deformation behavior of precipitation-strengthened Mg-Nd alloys, in situ synchrotron x-ray diffraction is employed to examine load transfer between matrix and precipitates, and dislocation-precipitate interactions are examined

Victoria Miller and Sean Agnew are the JOM advisors for the Magnesium Committee of the TMS Light Metals Division, and guest editors for the topic Integrated Computational Materials Engineering of Magnesium. using transmission electron microscopy. It is concluded that dislocation-precipitate interactions play a much more important role in the strengthening, whereas the authors of the first paper highlight the fact that coherency strain interactions between matrix and precipitate play a significant role in determining precipitate shapes.

The third article in this topic focuses on characterization of the relationship between material preprocessing and mechanical behavior. In the manuscript "Improved Stretch Formability of AZ31 Magnesium Thin Sheet Induced by 10-12 Tensile Twins" by Lifei Wang et al., material is initially compressed in the plane of the sheet to induce twinning. The authors demonstrate that the presence of these preexisting twins increases not only strength, but also elongation to failure and formability. New connections between microstructure and properties, such as this, will provide important challenges (use cases) for ICME groups, such as PRISMS.

Next, the topic focuses on process characterization; understanding local microstructural variability introduced by material processing techniques is critical to development of a robust ICME framework. In a two-part paper, $\mathrm{Xu}$ Bo $\mathrm{Li}$ et al. describe the local microstructural variability introduced during a novel extrusion technique: continuous variable cross-section direct extrusion (CVCDE). In the first part, the authors focus on texture evolution, while in the second part the dynamic recrystallization behavior resulting from this manufacturing technique is examined.

The series concludes with an industrial case study by J.P. Weiler, where the ICME paradigm is integrated into the design of die-cast magnesium components. In this study, local microstructure is predicted based on mold-filling, and the results are utilized to predict site-specific mechanical properties. Excellent matches between predicted and actual mechanical properties are demonstrated for AM60B die-cast into commercially realistic 
geometries. This promises to enable component design tailored to local mechanical properties, enabling greater mass reduction when incorporating magnesium alloys into engineering systems.

The following papers are published under the topic "Integrated Computational Materials Engineering of Magnesium (ICME of Mg)" in the October 2018 issue (vol. 70, no. 10) of JOM and can be accessed via the $J O M$ page at http://link.springer.c om/journal/11837/70/10/page/1:

- "PRISMS-An Integrated, Open Source Framework for Accelerating Predictive Structural Materials Science" by L.K. Aaegesen, J.F. Adams, J.E. Allison, B. Andrews, V. AraulloPeters, T. Berman, Z. Chen, S. Daly, S. Das, S. DeWitt, S. Ganesan, K. Garikipati, V. Gavini, A. Githens, M. Hedstrom, Z. Huang, H.V. Jagadish, J.W. Jones, J. Luce, E.A. Marquis, A. Misra, D. Montiel, P. Motamarri, A.D. Murphy, A.R. Natarajan, S. Panwar, B. Puchala, L. Qi, S. Rudraraju, K. Sagiyama, E.L.S. Solomon, V. Sundararaghavan, G. Tarcea, G.H. Teichert, J.C. Thomas, K. Thornton, A. Van der Ven, Z. Wang, T. Weymouth, and C. Yang

- "Understanding the Strengthening Effect by $\mathrm{SS}_{1}$ Precipitates in Mg-Nd Using In Situ Syn- chrotron X-ray Diffraction” by B. Zhou, L. Wang, G. Zhu, J. Wang, W. Wen, and X. Zeng

- "Improved Stretch Formability of AZ31 Magnesium Thin Sheet Induced by $\{10-12\}$ Tensile Twins" by L. Wang, M. Cao, W. Cheng, H. Zhang, X. Cao, and E. Mostaed

- "Microstructural Characteristics of AZ31 Magnesium Alloy Processed by Continuous Variable Cross-Section Direct Extrusion (CVCDE): Part 1: Texture Evolution" by X.B. Li, F. Li, and X.W. Li

- "Microstructural Characteristics of AZ31 Magnesium Alloy Processed by Continuous Variable Cross-Section Direct Extrusion (CVCDE): Part 2: Dynamic Recrystallization" by X.B. Li, F. Li, and X.W. Li

- "Incorporating an ICME Approach into Die-Cast Magnesium Alloy Component Design" by J.P. Weiler

\section{REFERENCES}

1. S.R. Agnew, J.J. Bhattacharyya, F. Wang, and P.J. McQuade, in Magnesium Technology 2017, ed. by K.N. Solanki, D. Orlov, A. Singh, and N.R. Neelameggham (The Minerals, Metals, and Materials Society, Pittsburgh, 2017), pp. 1315.

2. T.T. Wong, JOM, 68, 2029 (2016).

3. T.T. Wong, JOM, 69, 879 (2017). 